\title{
Las matemáticas en los tiempos del Coronavirus
}

\author{
Gema Alejandrina Mercado Sánchez ${ }^{1}$
}

Saludo con aprecio la publicación de un volumen más de la Revista Educación Matemática que nos ha acompañado desde hace más de 32 años ininterrumpidos para garantizar un espacio libre al razonamiento matemático y sus retos educativos.

Ahora, en pleno momento de oleadas diferidas de la pandemia COVID-19, la ciencia y la técnica se revaloran en la discusión global procurando documentar lo que hacemos, lo que aprendemos diario y lo que quisiéramos predecir. La matemática se anuncia en cadena nacional, en voz de médicos, epidemiólogos, especialistas de salud pública y políticos. La ciudadanía se apresta a entender las tablas y gráficas. Nos llaman a cambiar la curva para mitigar los efectos de la fatal pandemia. Nos piden que nuestro confinamiento, en medida de sana distancia, modifique la dinámica del comportamiento de contagios y buscar, entre todos, "aplanar la curva". Muchos, sin saberlo, participan de un esfuerzo mundial para cambiar el valor de la segunda derivada en la curva que parece advertir una mayor amenaza de la pandemia COVID-19. Aún más, gráficas coloridas inundan las pantallas explicando que existen diferentes modelos para enfrentar la amenaza global y el cálculo multivariado se parafrasea de diferentes formas: los modelos de contención y mitigación dependen de diversas

1 Secretaría de Educación de Zacatecas, México, gemaa.mercado@gmail.com 
circunstancias: de la economía, de la cultura, del régimen político, de la capacidad hospitalaria, de los hábitos alimenticios, de la salud pública y muchas más variables. En cada país se analiza: ¿cómo somos? ¿qué tenemos? ¿cómo lo haremos distinto? La solución no es copiar lo que otros hacen porque las variables son diferentes. Es decir, somos distintos. El problema es profundamente multivariable, no lineal, difícil predecir el final.

Y el despertar humanitario llamando a la solidaridad, a la reflexión, a la perspectiva diferente. La economía del mercado es brutal porque es muy celosa, ¿salud o economía? Todos claman "la salud es lo más importante, iparemos!". Y la economía se desploma. Y la matemática lo documenta: otras gráficas y curvas aparecen, éstas para explicar que la economía va cayendo, que el índice del PIB se redujo, que la balanza comercial se desequilibró, que el daño económico será inmenso. La matemática no se puede esconder ni desprestigiar como una asignatura aburrida, repetitiva, estéril. No es un lujo de algunos expertos, todos queremos entender, ¿adónde va la curva? ¿qué anticipa? La respuesta no es sencilla. Es ciencia, es un modelo matemático, que cambia según cambian las variables en cada país, en cada territorio. Es una aproximación. Sabemos tanto, pero la realidad se nos presenta sin exhibirse por completo y es mutante vertiginosa, se escabulle a la predicción científica. Abundan las interpretaciones ingenuas que junto con las fake news abruman las redes sociales, ¿cómo explicar que en San Diego haya 80 infectados mientras que del lado mexicano sólo seis? La respuesta está en los modelos matemáticos de flujo migratorio y movilidad poblacional. Pero esto no se ignora, porque lo que importa es generar confusión, así, la política intenta sustituir a la ciencia y la técnica.

La matemática puede considerarse un aditamento extraordinario a nuestro lenguaje natural, incorpora una posibilidad para describir aspectos y relaciones cuantitativas del mundo que nos rodea, y nos permite capturar, en las relaciones entre funciones, la dinámica del universo, su forma y complejidad. Los seres humanos hemos podido construir el lenguaje y una estructura interna de variables, ecuaciones y desigualdades geometrías y capacidades de análisis de grandes datos para describir, cuantitativamente, la esencia fundamental de aspectos de nuestra realidad. La obra intelectual ha sido un ejercicio portentoso y global, de abstracción de la realidad. La representación tiene lógica y belleza. La abstracción impone una gran asepsia, sólo lo fundamental puede participar. No todos los detalles de la realidad caben; sólo ella se representa a sí misma completa. Y de esa misma selección entre lo esencial y lo extrínseco surge la belleza que se compacta en una 
ecuación, en una gráfica, en un conjunto de relaciones de funciones. Y así, capturada la esencia, paradójicamente, se libera para conocer su pasado, su dinámica, su porvenir. Y se establece el desafío constante, mientras más detalles incorporamos al modelo matemático, más complejo se vuelve resolverlo y conocer; la belleza interna también se compromete. Por otro lado, mientras más elevada sea la abstracción, más perdemos la realidad que queremos capturar en la representación matemática. La delgada línea, entre abstracción y realidad, es frágil. Los grandes han sido certeros. ¿Quién no reconoce la imagen de $F=m a$ ? ¿̇o aquella de $E=m c^{2}$ ? Aun los legos presienten su simetría y su poder.

La modelación matemática es una estrategia del razonamiento para traducir, interpretar de forma compacta y cuantitativa, el comportamiento de nuestro universo, de la naturaleza, de la sociedad, de la economía y un interminable etcétera. Extendiendo nuestro lenguaje y codificando magnitudes podemos interpretar nuestro entorno, reconocer su estructura y su dinámica, su pasado y su presente. Es tan poderosa esa posibilidad, que es inconcebible el desarrollo técnico y científico, ni el mundo como lo conocemos sin el gran fundamento representativo de la matemática. Y esta ciencia, con su propia sintaxis y semántica, no es exacta, ni rígida, ni inhumana, como sus detractores la anuncian sin gracia. Al contrario, es una aproximación sustantiva, aunque es precisa en su propia lógica interna. Se deriva de una actividad profundamente humana, deviene del triunfo de la argumentación sobre el dogma. En el ejercicio matemático se convoca a los presentimientos fundamentados, a la emoción de lo posible y de lo imposible, a la ilusión de la esperanza sobre el desaliento. La matemática evoluciona, crece, se afina, incorpora nuevas rutas de pensamiento y estructuras, se vincula con otras ciencias para construir nuevas formas del pensamiento y nacen nuevas áreas del conocimiento, nuevas ciencias. Es profundamente humana y sólo el optimismo explica su origen y evolución. Las matemáticas son una de las creaciones intelectuales más sofisticadas del razonamiento humano y junto con las otras ciencias, incluyendo las humanas, el arte y la ética, representan los aspectos más brillantes de nuestra civilización. Son así, el único asidero de sobrevivencia de la especie humana.

En la inercia previa a la contingencia sanitaria global por la pandemia, hasta la ciencia parecía prescindible. Hoy todos somos convocados a revisar el modelo de vida, el modelo económico y el modelo de crecimiento. La ciencia salta al escenario principal y se reinstala en la necesidad de que, en tiempos sombríos, el brillo más portentoso de la creación humana señale el camino. Coinciden los antropólogos, los epidemiólogos, los religiosos y los políticos: la 
vida futura debe ser diferente. Debe incluir la ética, la generosidad, el reconocimiento de revalorar la otredad y desmontar el vínculo fatal de economía y modo de vida vertiginoso y con programación acrítica. La educación de las ciencias, su entendimiento masivo y difusión renuevan su pertinencia. La ciencia, y las matemáticas particularmente, como todas las obras humanas, son también elementos que modifican la vida de las civilizaciones. En la discusión pública, se anticipa con cierta claridad el papel que ocupan las matemáticas en la distribución de los saberes, en la legitimación social, en la exclusión y en la desigualdad y su profundo impacto en la salud pública.

Por eso, la Secretaría de Educación del Gobierno del Estado de Zacatecas responde al Ilamado y se compromete a apoyar la edición de la Revista Educación Matemática en este año axial, el año que nadie olvidará, el de la pandemia COVID-19. Queremos que la revista continúe sus 32 años de educación y difusión de la Educación Matemática. Ojalá su tarea educativa se acentúe y pueda dedicar un número especial a la epidemiología matemática; a la economía matemática y financiera que explique el efecto y consecuencias múltiples de la pandemia que nos ha tocado vivir. La epidemiología es una ciencia cuantitativa, pero detrás de cada dato, de cada cifra hay personas y familias. Ojalá haya matemáticas/os que expliquen ese vínculo esencial entre los modelos para contener la pandemia del COVID-19 dependiendo de variables como la pobreza, la migración y la desigualdad social que parecen describir el entorno nacional, y en particular el de Zacatecas, en el cual se desenvuelve el gran reto de salud pública que enfrentamos.

Es nuestro anhelo y queremos contribuir a que la Revista Educación Matemática siga siendo un referente obligado para los estudiosos de esta disciplina en el mundo hispanoparlante. Ojalá otras instituciones y actores revaloremos su importancia en la educación de nuestros pueblos para evitar que sigamos siendo únicamente testigos o víctimas fatales de una pandemia como la que hoy vivimos.

Gema Alejandrina Mercado Sánchez

Domicilio postal: López Portillo \#305, C.P. 98618

Guadalupe, Zacatecas, México

Teléfono:

01 (492) 92-39600 